\section{Common pain syndromes and their management}

\section{J. E. Charlton MB BS FFARCS}

Anaesthetists are concerned with the management of pain throughout their working day. Traditionally this is the responsibility for abolishing pain associated with surgical or medical procedures. Since the advent of pain relief clinics and the continued growth of these facilities, anaesthetists are now being asked to deal with acute and chronic pain arising from other causes.

Pain is defined by the International Association for the Study of Pain as "a sensory or emotional experience associated with actual or potential tissue damage, or described in terms of such damage." This definition applies equally to acute and chronic pain and includes the substantial numbers of patients who have a psychiatric or psychological basis for their pain complaint. It is this behavioural component, and the difficulties experienced by the non-specialist in assessing this aspect of any pain complaint, that may intimidate anaesthetists from managing patients with pain complaints that do not fall within their routine practice.

It should be emphasized that the symptom of pain should not be treated in isolation. A diagnosis must be established before treatment is commenced, as misdiagnosis may lead to consequent mistreatment which, in turn, may have acute repercussions for both the patient and the treating physician. Establishing the correct diagnosis may require knowledge of several different disciplines. If there is any doubt, help should always be obtained. With regard to behavioural and emotional factors there are several reliable questionnaires that can be used to assess the need for further evaluation of the patient by an appropriate specialist. $^{2-5}$

Despite this there are clinical syndromes which can be treated with great benefit by the non-specialist anaesthetist. These are all conditions that can be helped by relatively simple interventions. It is also important to emphasise that treatment should begin as early as possible after the diagnosis has been established. It is likely that acute intervention will terminate or minimise the progression from acute pain into chronic pain, and thus reduce the devastating physical and emotional changes that characterise chronic intractable pain.

\section{Sympathetically maintained pain}

A syndrome of diffuse limb pain that usually follows a noxious stimulus. The syndrome may spread independently of the site or cause of the precipitating event and may present without a recognisable pattern of dermatomal or peripheral nerve distribution. There may be marked features of sympathetic overactivity which include disturbed blood flow, disturbances of sweating, and oedema. The changes in autonomic activity may be associated with sensory changes such as hypo- or hyperaesthesia and allodynia, and motor changes such as weakness and tremor. This syndrome includes conditions such as causalgia, reflex sympathetic dystrophy, Sudeck's atrophy and the algodystrophies.

Classically, causalgia is associated with neural damage, usually following lesions of the medial cord of the brachial plexus or median nerve in the upper extremity, or sciatic nerve in the leg. Sympathetically maintained pain without neural injury may follow crush or blast injuries, strain/sprain injuries, fractures or lacerations. Not infrequently the precipitating event may have been so trivial that the patient cannot recall it. Pain is continuous, severe and is described as burning. It may be superimposed on pain that is deep, shooting, stabbing or crushing. Pain may be exaggerated by trivial stimuli and the patient may go to extraordinary lengths to avoid an exacerbation of the pain.

The mechanism of action is incompletely understood, but there is no doubt that overactivity of the sympathetic nervous system plays a major role in maintainng the painful condition. ${ }^{6,7}$ Initial treatment is appropriate sympathetic blockade carried out frequently, two to three times per week, in conjunction with aggressive physical therapy. Sympathetic blockade can be achieved by serial use of conventional sympathetic blockade with local anaesthetic drugs, ${ }^{8}$ or by intravenous regional sympathetic block using an adrenergic blocking agent such as guanethidine. 9 Several other drugs have been given by this method in the management of sympathetically maintained pain, and these include alpha and beta adrenergic blocking agents, calcium channel blockers and serotonin antagonists. All have been reported as offering some

Department of Anaesthesia, Royal Victoria Infirmary, Newcastle upon Tyne, England. 
success. Other readily available methods of treatment include the use of transcutaneous electrical nerve stimulation [TENS], steroids, antidepressants and anticonvulsants, in addition to the oral use of those drugs mentioned previously. Conventional analgesics such as nonsteroidal anti-inflammatory drugs [NSAID's] and opioids are generally ineffective in the management of this syndrome.

\section{Neurogenic pain}

Neural blockade is frequently of help in the diagnosis of neurogenic pain, and conditions such as acute shingles, post-herpetic neuralgia, some entrapment syndromes and facial pain such as trigeminal neuralgia will benefit from neural blockade, at least in the short term. ${ }^{10,11}$ There is some evidence that the overall incidence of post-herpetic neuralgia is unaffected by nerve blocks no matter how early in the course of the disease these are instituted. However, there can be little doubt that the severity of the pain experienced in the initial stages of this disease can be ameliorated considerably by serial nerve blocks. Treatment of neurogenic pain should be instituted as early as possible and include the use of TENS and "centrally acting" analgesics such as antidepressants and anticonvulsants, as well as nerve blocks. ${ }^{12,13}$

\section{Phantom limb pain}

Phantom limb and stump pain are common problems in amputees. ${ }^{14-16}$ The pain may be similar to that experienced preoperatively and treatment is frequently ineffective. ${ }^{17}$ It is likely that only preoperative intervention can influence the incidence and severity of postoperative phantom and stump pain. A recent study has shown a reduction in the incidence of postoperative phantom pain when regional anaesthesia was used for the operation. Where pain relief was supplied by regional techniques for three days preoperatively, and extended to provide anaesthesia for the procedure, there was no postoperative phantom or stump pain for up to one year afterward. ${ }^{18}$ If these findings can be confirmed with large-scale clinical trials this represents a vital role for the anaesthetist in the prevention and abolition of a major pain problem.

\section{Myofascial pain}

Myofascial disorders are a common cause of musculoskeletal pain. They are infrequently recognised and thus this group of painful conditions remains inadequately treated. ${ }^{19,20}$ Myofascial pain may affect virtually everyone and may be initiated by trauma, stress or fatigue. Examples of myofascial pain range from the severe unrelenting pain that follows a whiplash injury, to a more diffuse discomfort associated with overuse or fatigue.

Myofascial pain is associated with definite trigger points which produce predictable patterns of pain when stimulated. Recognition of the specific referred-pain pattern of each muscle is the key to understanding this group of conditions. Once initiated the muscular trigger points may become self-perpetuating, and lead to a continuing cycle of pain and muscle spasm. This may occur despite adequate treatment of the precipitating stimulus. Treatment is the injection of local anaesthetic or saline into the trigger point, followed by physiotherapy.

\section{Low back pain}

The largest group of patients attending any pain clinic is usually that presenting with low back pain. This is a symptom of a large number of different syndromes which are classified into several categories according to their assumed pathogenesis. Examples include inflammatory, degenerative, structural, traumatic, muscular and ligamentous. These include malignancy, visceral disease, vascular disease and myriad conditions of bone, joint and surrounding structures. Regrettably, the vast majority of patients does not have a recognisable or readily treatable cause for their low back pain, and this leads to a disproportionate degree of suffering for the patient and family.

Acute back pain is usually a self-limiting condition, which disappears without medical consultation. ${ }^{21.22}$ However, there is a high recurrence rate and there are data which show that each recurrence is more severe and long-lasting. ${ }^{23-25}$ This creates an enormous number of people who suffer from chronic and recurrent low back pain. These patients represent a vast burden to the taxpayer and the health care system. There are data to suggest that early intervention during acute episodes can slow down the slide into chronicity.

Bedrest and medication are the first-line therapy. This method of treatment is effective in the majority of cases, but may lead to problems with prolonged use. Failure to obtain pain relief within two weeks should lead to a reappraisal of treatment, and consideration should be given to other forms of therapy which may include physiotherapy, TENS, surgery and the use of epidural injections, with or without steroids. Reviews of the use of epidural steroids for both acute and chronic low back pain indicate they may be helpful in rehabilitation, and this suggests a role for the anaesthetist. However, it should be borne in mind that the vast majority of papers upon this subject are not scientifically valid. ${ }^{26,27}$

\section{Cancer pain}

The anaesthetist has a major role to play in the management of pain arising from cancer. Often those caring for a patient with terminal illness are intimidated by the drugs and dosages required for the control of pain, and the 
anaesthetist's knowledge of strong analgesics can be put to effective use. Altematively, it may be possible to avoid the use of powerful and depressant analgesics such as the opioids by the selective use of other agents and the judicious use of destructive techniques.

Neurodestructive techniques are not the complete answer to the pain arising from malignancy, and specific analysis of the pain must be made to identify the sort of therapy likely to be most helpful. ${ }^{28}$ However, where the patient has a limited life expectancy and the pain has responded appropriately to a diagnostic nerve block, a neurolytic block may yield prolonged analgesia for the rest of the patient's life. Examples include the use of coeliac plexus or lumbar sympathetic blockade. ${ }^{29}$ These are techniques that can be performed by any anaesthetist with the appropriate equipment, and are especially valuable in the minority of patients where other forms of therapy have failed.

There are other procedures that can be of benefit in pain arising from malignancy. Subarachnoid neurolysis may be of use on rare occasions. The major drawback to the use of this technique is the limited duration of pain relief, which varies from two weeks to over a year, but with an average of only two to four months. ${ }^{30,31}$ An alternative is the use of epidural phenol, ${ }^{32}$ or the implantation of epidural or central venous lines for the long-term infusion of opioids. ${ }^{33}$

\section{Summary}

Every anaesthetist can apply knowledge or skills used in routine clinical practice to make a significant contribution to the management and control of acute and chronic pain. This is true whether the pain arises from malignant or non-malignant causes.

\section{References}

1 International Association for the Study of Pain, Subcommittee on Taxonomy. Classification of chronic pain. Pain 1986; Suppl 3.

2 Pilowsky I, Spence ND. Patterns of illness behaviour in patients with intractable pain. J Psychosom Res 1975; 19: 279-87

3 Pilowsky I, Spence ND. Manual for the Illness Behaviour Questionnaire [IBQ] 2nd ed. Adelaide: University of Adelaide, Department of Psychiatry, 1983.

4 Zigmond AS, Snaith RP. The hospital anxiety and depression scale. Acta Psychiat Scand 1983; 67: 361-70.

5 Williams $R C$. Toward a set of reliable and valid measures for chronic pain assessment and outcome research. Pain 1988; 35: 239-51

6 Roberts WJ. A hypothesis on the physiological basis for causalgia and related pain. Pain 1986; $24: 297-311$.

7 Devor $M$, Janig W. Activation of myelinated afferents ending in a neuroma by stimulation of the sympathetic supply in the rat. Neurosci Lett $1981 ; 24: 43-7$.

8 Bonica $J J$. Causalgia and other reflex sympathetic dystrophies. In: Bonica JJ, Liebeskind JG, Albe-Fessard DG (Eds.). Advances in Pain Research and Therapy, Vol 3. New York: Raven Press, 1979. 141-66.

9 Hannington-Kiff JG. Pain Relief. Philadelphia: Lippincott, 1974. 68-79.

10 Loh L, Nathan PW. Painful peripheral states and sympathetic blocks. J Neurol Neurosurg Psychiat 1978; 41: 664-71.

11 Loh L, Nathan PW, Schott GD. Pain due to lesions of central nervous system removed by sympathetic block. Br Med J 1981; 282: 1026-8.

12 Watson CP, Evans RJ, Reed K, Merskey $H$, Goldsmith L Warsh $J$. Amitryptiline vs. placebo in postherpetic neuralgia. Neurology 1982; 32: 671-3.

13 Max MB, Culnane $M$, Schafer $S C$ et al. Amitryptiline relieves diabetic neuropathy pain in patients with normal or depressed mood. Neurology 1987; 37: 589-97.

14 Jensen TS, Krebs B, Nielsen J, Rasmussen P. Phantom limb, phantom pain and stump pain in amputees during the first six months following limb amputation. Pain 1983; 17: 243-56.

15 Sherman RA, Sherman CJ. Prevalence and characteristics of chronic phantom limb pain among American veterans. Amer J Phys Med 1983; 62: 227-38.

16 Sherman RA, Sherman CJ, Parker L. Chronic phantom and stump pain among American veterans: results of a survey. Pain 1984; 18: 83-95.

17 Sherman RA, Sherman CJ, Gall NG. A survey of current phantom limb pain treatment in the United States. Pain 1980; 14: 85-99.

18 Bach $S$, Noreng MF, Tjellden NU. Phantom limb pain in amputees during the first twelve months following limb amputation, after preoperative lumbar epidural blockade. Pain 1988; 33: 297-301.

19 Sola A. Upper extremity pain. In: Wall PD, Melzack R (Eds.). Textbook of Pain. Edinburgh: Churchill Livingstone, 1984, 252-62.

20 Simons $D G$, Travell JG. Myofascial pain syndromes. In: Wall PD, Melzack R (Eds.). Textbook of Pain. Edinburgh: Churchill Livingstone, 1984; 263-76.

21 Nachemson $A L$. Pathophysiology and treatment of back pain: a critical look at the different types of treatment. In: Buerger AA, Tobis JS (Eds.). Approaches to the validation of manipulation therapy. Springfield I1 1.: Charles C Thomas, 1977. 769-79.

22 Dixon ASJ. Diagnosis of low back pain - sorting the complainers. In: Jayson $\mathrm{M}$ (Ed.). The lumbar spine and back pain. New York: Grune and Stratton, 1976. 77-92.

23 Horal $J$. The clinical appearance of low back disorders in 
the City of Gothenberg, Sweden. Acta Orthop Scand [Suppl] 1969; 118: 8-73.

24 Dehlin $O$, Hedenrud $B$, Horal J. Back symptoms in nursing aids in a geriatric hospital. Scand J Rehabil Med 1976; 8: 47-53.

25 Hirsch C, Jonsson B, Lewin T. Low-back symptoms in a Swedish female population. Clin Orthop 1969; 63: $171-6$.

26 Kepes ER, Duncalf D. Treatment of backache with spinal injections of local anaesthetics, spinal and systemic steroids. A review. Pain 1985; 22: 33-47.

27 Benson HT. Epidural steroid injections for low back pain and lumbosacral radiculopathy. Pain 1986; 24: 27795.

28 Arner S, Meyerson BA. Lack of analgesic effect of opioids on neuropathic and idiopathic forms of pain. Pain 1988; 33: 11-23.

29 Charlion JE. Current views on the use of nerve blocking in the relief of chronic pain. I $n$ : Swerdlow M (Ed.). The therapy of pain. Lancaster: MTP Press, 1986. 133-64.

30 Wood $K M$. The use of phenol as a neurolytic agent: a review. Pain 1978; 5: 205-29.

31 Swerdlow $M$. Intrathecal and extradural block in pain relief. In: Swerdlow M (Ed.). Relief of intractable pain. 3rd ed. Amsterdam: Elsevier, 1983. 175-214.

32 Racz GB, Sabonghy $M$, Gintautas J, Kline WM. Intractable pain therapy using a new epidural catheter. J Am Med Assoc 1982; 248: 570-81.

33 Charlton JE. Drug treatment of chronic pain. In: Swerdlow M, Charlton JE (Eds.). Relief of intractable pain. 4th ed. Amsterdam: Elsevier, 1989. 60-134. 